Original Research Paper

\title{
Cytogenetic Analysis among Train Depot Workers Exposed to Total Volatile Organic Compounds
}

\author{
${ }^{1}$ Normah Awang, ${ }^{1}$ Siti Adillah Isah and ${ }^{2}$ Asmah Hamid \\ ${ }^{I}$ Environmental Health and Industrial Safety Programme, Faculty of Health Sciences, \\ Universiti Kebangsaan Malaysia, Jalan Raja Muda Abdul Aziz, 50300 Kuala Lumpur, Malaysia \\ ${ }^{2}$ Biomedical Science Programme, School of Diagnostic and Applied Health Sciences, Faculty of Health Sciences, \\ Universiti Kebangsaan Malaysia, Jalan Raja Muda Abdul Aziz, 50300 Kuala Lumpur, Malaysia
}

Article history

Received: 15-02-2015

Revised: 20-03-2015

Accepted: 06-06-2015

Corresponding Author:

Normah Awang

Environmental Health and

Industrial Safety Programme,

Faculty of Health Sciences,

Universiti Kebangsaan

Malaysia, Jalan Raja Muda

Abdul Aziz, 50300 Kuala

Lumpur, Malaysia

Email: awang_normah@yahoo.com

Abstract: Occupational exposure to toxic chemicals such as Total Volatile Organic Compounds (TVOC) from diesel engine exhaust implicates genotoxic risk. The objective of this study was to determine the DNA damage among KL Sentral depot workers exposed to TVOC by means of cytogenetic analysis. Data were obtained partially from disseminated questionnaires and buccal cells samples were collected from a total of 27 depot workers and 10 office workers by using wooden tongue depressor. TVOC measurement was carried out by using Photoionisation Detector (PID). 4 sampling points were selected, namely Locomotive (LOCO), Power Generating Car (PGC), refuelling of diesel and coach. Cytogenetic analysis was done by using Acridine Orange (AO) staining. Micronucleus (MN) frequency as a biomarker for DNA damage was scored from 1,000 cells per sample observed under fluorescence microscope. The results showed that the overall means of concentrations for TVOC were $0.1 \pm 0.1$, $0.0 \pm 0.0,0.1 \pm 0.0$ and $0.1 \pm 0.0$ in LOCO, PGC, refuelling of diesel and coach, respectively. TVOC concentration measured did not exceed the permissible level based on DOSH 2010. For the cytogenetic analysis, depot workers showed significantly higher $\mathrm{MN}(\mathrm{p}<0.001)$ than the office workers. Besides that, the sociodemographic factors (e.g., age, smoking status) and the $\mathrm{MN}$ frequency of the depot workers were also significantly higher than the office workers. However, there was no significant difference in MN frequency between workers wearing Personal Protective Equipment (PPE) and without wearing PPE [MN $(\mathrm{p}=0.491)]$. In addition, there was a positive correlation between the working period (year) and the frequency of $\mathrm{MN}$ with $\mathrm{r}^{2}=0.54, \mathrm{p}<0.01$. The result also showed that exposure to TVOC was a significant predictor of the $\mathrm{MN}$ frequency $(\mathrm{p}<0.001)$. On the other hand, smoking status did not show any significant association with the frequency of MN. These findings showed that depot workers exposed to TVOC were prone to DNA damage. Therefore, biomonitoring of DNA damage among depot workers is recommended in order to improve occupational health and safety condition in their workplace.

Keywords: Total Volatile Organic Compound (TVOC), Genotoxic, Buccal Cells, Micronucleus (MN)

\section{Introduction}

Individual exposure to certain air pollutants has been identified to cause DNA damage that increases the rate of occurrence of acute and chronic diseases such as cancer (Tovalin et al., 2006). However, the severity depends on the type of contaminants, toxicity, magnitude, duration and frequency of exposure to these pollutants (WHO, 1999).

There are a number of reports on the exposure towards Total Volatile Organic Compounds (TVOC) in occupational environment. Several carcinogenic agents have been identified in contaminated indoor air. TVOC are among the most common air pollutants that may 
have damaging effects on the health of the workers. According to the Environmental Protection Agency (EPA, 2012), some of the TVOC have been identified to have the potential to cause health problems such as mild inflammation and irritation of the respiratory tract, besides causing severe health problems such as cancer. Many hazardous chemicals can be found in the depot area, such as paints, fuels, solvents, dry cleaning agent and diesel fume. These chemicals contribute to the release of TVOC in indoor air environment.

The World Health Organisation (WHO) describes that exhaust diesel, which contains gas components such as benzene and formaldehyde, is among the volatile organic compounds classified as carcinogenic to human. Some studies have proved that the individual exposure to diesel fumes increases the risk of stomach and lung cancer (Silverman et al., 2012; Sjödahl et al., 2007). DNA damage is probably the most important fundamental cause of developmental and degenerative diseases (Gemitha and Sudha 2013). Hence, biomonitoring of human genotoxicity induced by environmental exposure to genotoxic agents is highly essential.

Stich et al., (1983) state that the micronucleus in buccal cells is a popular biomarker to determine the DNA damage caused by exposure to environmental pollutants, lifestyle factors (e.g., alcohol consumption, smoking), medical techniques (e.g., radiotherapy chemotherapy) and genetic damage in the repair of DNA damage. Study by Kayal et al., (1993) also found that the analysis of micronucleus in buccal cells is a sensitive method to identify genetic damage in human populations. Cytogenetic analysis using the micronucleus assay has been found to be a useful tool as a genotoxicological biomarker for the early detection of disease-related changes.

Train depot workers are engaged in different production process which involves the exposure to number of chemicals, high temperature and personal hygiene varies in their workplace (Hedenstedt et al., 1977). There is no sufficient information for the assessment of genotoxicity concerning the occupational exposure to train depot workers. Considering these the present study aimed to investigate the genotoxic effects in buccal cells in an exposed population of train depot workers in Malaysia using MN test.

\section{Subject and Methods}

\section{Study Population}

A total of 37 individuals (27 depot workers and 10 controls) were recruited in this study. The workers had varying durations of exposure (4-37 years) and in the age group of 25-53 years old.

Depot workers were employed in the daily maintenance includes cleaning, repairs and periodic inspections of locomotives, coaches and power generating car. A group of 10 office workers from the same company was also recruited. Subjects who had cancer and a history of cancer were excluded in this study. The selection criteria were based on a questionnaire, which covered standard demographic questions (sex, age, smoking status, medical history) and occupational questions (duration of exposure by year and usage of personal protection equipment).

\section{Assessment of Exposure to TVOC}

Air concentration of TVOC inside the depot areas was measured by photoionisation detector. 4 sampling points were selected, namely Locomotive (LOCO), Power Generating Car (PGC), refuelling of diesel and coach. Two 5 min measurements (one in the morning, between 10 and $11 \mathrm{AM}$ and the other in the afternoon, between 3 and 4 PM) were done in each point at the depot areas.

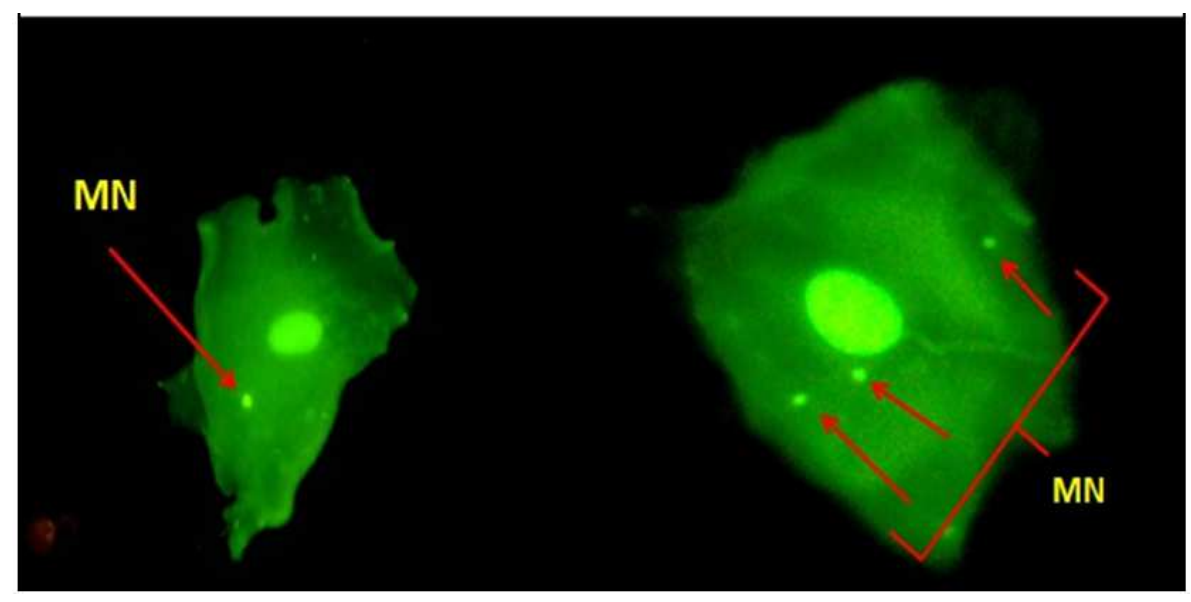

Fig. 1. Micronucleated cell (arrow). 400× magnification. Acridine orange staining 


\section{Analysis of Micronuclei in Buccal Cells}

Buccal cells were collected from each subject by using wooden tongue depressor according to the criteria established by Tolbert et al. (1992). The method was by scrubbing the inside cheeks of the mouth. After that, the buccal cells collected were agitated in $5 \mathrm{~mL}$ cold buffer solution and the suspension was centrifuged at 2,000 rpm for $10 \mathrm{~min}$. Cell suspension of $200 \mu \mathrm{L}$ was smeared on precleaned slides, fixed and stained with Acridine Orange (AO). Slides were evaluated under a fluorescence microscope with $400 \times$ magnification (Fig. 1). For each individual, a total minimum of 1,000 epithelial cells were scored for analysis of MN.The criteria developed by Tolbert et al. (1992) were used for counting the micronuclei, as follows:

- Parameters for identifying micronucleus were rounded smooth perimeter;

- Less than a one-third of the diameter of associated nucleus;

- Staining intensity similar to nucleus;

- Texture similar to main nucleus;

- Same focal plane as main nucleus;

- Absence of overlap with or bridge to nucleus

- Dead or degenerating cells (e.g., karyolysis, karyorrhexis, nuclear fragmentation) were excluded from evaluation

\section{Results}

The two groups namely depot workers and office workers were comparable in terms of age, race, smoking status, working period (by year) and Personal Protective Equipment (PPE) usage (Table 1). The overall means of concentration for TVOC were $0.1 \pm 0.1,0.0 \pm 0.0,0.1 \pm 0.0$ and $0.1 \pm 0.0$ in LOCO, PGC, refuelling of diesel and coach, respectively (Table 2).

\section{MN Frequencies}

The frequency (mean \pm S.E.) of MN per 1,000 cells in the depot workers $(1.22 \pm 0.12 \%)$ was significantly higher than in the office workers $(0.08 \pm 0.06 \%) \quad$ with $p<0.001 \quad$ (Fig. 2). The sociodemographic factors (e.g., age, smoking status) and the frequency of $\mathrm{MN}$ of depot workers were also significantly higher than the office workers. However, there was no significant difference of MN frequency between workers wearing PPE and without wearing PPE $(p=0.491)$. In addition, there was a positive correlation between the working period (year) and the frequency of $\mathrm{MN}$ with $\mathrm{r}^{2}=0.54, \mathrm{p}<0.01$.
Association between Exposure to TVOC and MN Frequency

The result showed that exposure to TVOC was a significant predictor of the MN frequency. After adjustment in age, race and smoking status, a higher MN frequency was found to be associated with exposure to TVOC $\left(\mathrm{r}^{2}=0.489 ; \mathrm{p}<0.001\right)$ (Table 3$)$.

Table 1. Demographic data of the depot workers (exposed group) and office workers (nonexposed group) to TVOC [data are reported as the \% of subjects]

\begin{tabular}{lll}
\hline & Depot workers & Office workers \\
\hline $\begin{array}{l}\text { Subjects (n) } \\
\text { Age }\end{array}$ & 27 & 10 \\
$\leq 40$ years old & $44 \%$ & $60 \%$ \\
$>40$ years old & $56 \%$ & $40 \%$ \\
Race & & \\
Malay & $78 \%$ & $90 \%$ \\
Indian & $22 \%$ & $10 \%$ \\
Smoking Status & & \\
Regular Smoker & $48 \%$ & $30 \%$ \\
Nonsmoker & $52 \%$ & $70 \%$ \\
Working period & & \\
$\leq 20$ years & $48 \%$ & $40 \%$ \\
$>20$ years & $52 \%$ & - \\
PPE usage & & \\
With PPE & $59 \%$ & \\
Without PPE & $41 \%$ & \\
\hline
\end{tabular}

Table 2. TVOC (mean \pm SD) for each sampling point at depot area

\begin{tabular}{lll}
\hline Sampling point & Mean \pm SD & $\begin{array}{l}\text { Standard concentration } \\
\text { (DOSH 2010) }\end{array}$ \\
\hline Locomotive & $0.1 \pm 0.1$ & $3 \mathrm{ppm}$ \\
PGC & $0.0 \pm 0.0$ & \\
Refuelling of diesel & $0.1 \pm 0.0$ & \\
Coach & $0.1 \pm 0.0$ & \\
\hline
\end{tabular}

Table 3. The mean frequency (mean $\pm \mathrm{SD}$ ) of micronuclei in exfoliated buccal epithelial cells of depot workers and office workers

\begin{tabular}{|c|c|c|c|}
\hline \multicolumn{2}{|l|}{ Study group } & $\mathrm{N}=37$ & $\mathrm{MN}($ Mean $\pm \mathrm{SD})$ \\
\hline \multirow[t]{9}{*}{ Depot workers } & Smoking Status & & \\
\hline & Regular Smoker & 13 & $1.29 \pm 0.64 *$ \\
\hline & Nonsmoker & 14 & $1.16 \pm 0.60 *$ \\
\hline & Age & & \\
\hline & $\leq 40$ years old & 12 & $0.83 \pm 0.56 *$ \\
\hline & $>40$ years old & 15 & $1.53 \pm 0.46^{*}$ \\
\hline & PPE Usage & & \\
\hline & With PPE & 16 & $1.24 \pm 0.64$ \\
\hline & Without PPE & 11 & $1.20 \pm 0.59$ \\
\hline \multirow[t]{5}{*}{ Office workers } & Smoking Status & & \\
\hline & Regular Smoker & 3 & $0.27 \pm 0.31$ \\
\hline & $\begin{array}{l}\text { Nonsmoker } \\
\text { Age }\end{array}$ & 7 & $0.00 \pm 0.00$ \\
\hline & $\leq 40$ years old & 6 & $0.00 \pm 0.00$ \\
\hline & $>40$ years old & 4 & $0.20 \pm 0.28$ \\
\hline
\end{tabular}




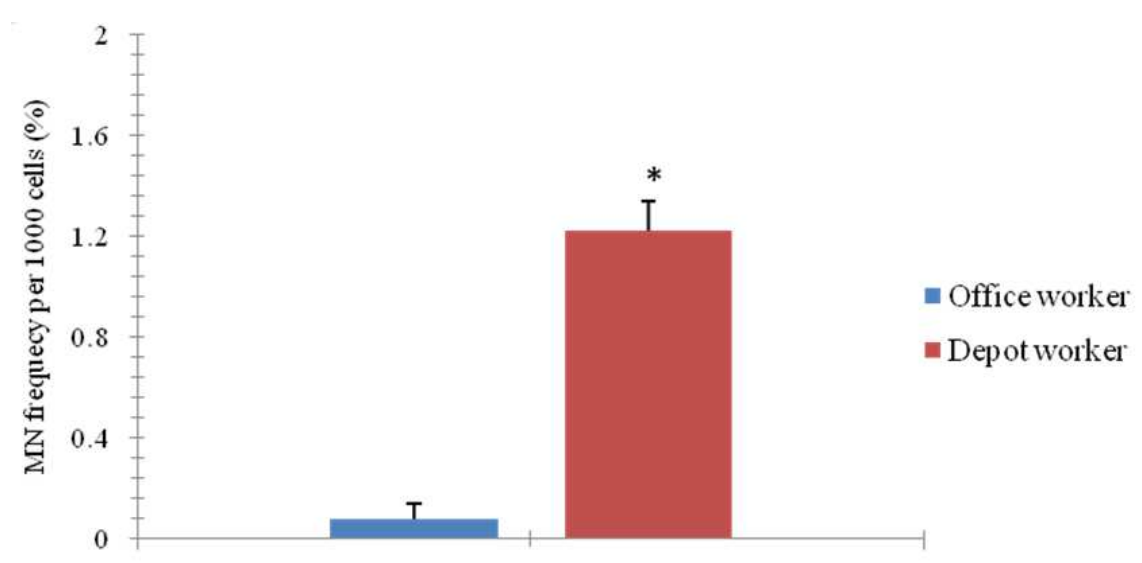

Fig. 2. Comparison of micronucleus frequency per 1,000 cells between two groups

\section{Discussion}

Occupational exposure to Total Volatile Organic Compounds (TVOC) implicates genotoxic risk. According to the Environmental Protection Agency (EPA, 2012), some TVOC can cause cancer to animal, while some are linked to cancer in human. However, the health effect of the TVOC exposure depends on the nature of the compound itself, the level of exposure and the length of exposure.

People are exposed to TVOC from various sources. These compounds are released from solvent-based material and paint used or stored in the building or in the maintenance operation area. Besides that, TVOC are also emitted from burning fuel and diesel exhaust. Storage of fuels and organic liquids found in the area of diesel locomotives also contributes to the emissions of TVOC including benzene, toluene and xylene (NPI, 2008).

In this study, micronucleus test was used to determine any DNA damage in buccal cells of depot workers who were exposed to the TVOC. MN assay is regarded as an important biomarker to predict the relative risk of occurrence of cancer (Stich et al., 1984).

Buccal cells are the first barrier for the inhalation and are capable of metabolising proximate carcinogens to reactive products (Liu et al., 1993; Vondracek et al. 2001). Approximately $90 \%$ of human cancers originate from epithelial cells (Rosin, 1992).

This study found an association between occupational exposure with TVOC and frequency of $\mathrm{MN}$. The frequency of $\mathrm{MN}$ in depot workers was higher than office workers. The higher $\mathrm{MN}$ among workers depots than office workers suggested that TVOC can induce genotoxicity in human chromosomes. The finding on higher frequency of MNC observed among the group exposed to TVOC was also in line with other studies especially those focusing on exposure to paint, diesel fuel and vehicle exhaust (e.g., Gajalakshmi et al., 2002; Çelik et al., 2003; Testa et al., 2005; Martins et al., 2009).

According to Pappas et al., (2006), tobacco smoke is known to contain numerous genotoxic chemicals. But, in this study, the results showed no significant association between smoking status and frequency of MN. Çelik et al. (2003) also found a significant increase in the frequency of $\mathrm{MN}$ in smokers compared to nonsmokers. However, a few studies did not find any relationship between the $\mathrm{MN}$ frequency and smoking habit (Bolognesi et al., 1997; Hessel et al., 2001). In addition, Martins et al. (2009) report that there is no significant correlation between frequency of $\mathrm{MN}$ and smoking among individuals exposed to fuel derivatives in the workplace.

Personal Protective Equipment (PPE) is equipment applied by workers in order to reduce their exposure to the risks and hazards in the workplace. Besides that, it is a last control measure after the engineering controls, work practices and administrative controls (OSHA, 2006). Moreover, the use of Personal Protective Equipment (PPE) has been identified as one of the factors that can affect the frequency of MN (Bolognesi et al., 2002; Bull, 2006). However, in this study, the results showed that the practice of wearing PPE among workers depots showed no significant difference in the frequency of MN per 1,000 cells. This may be caused by inappropriate and incomplete application of PPE.

The results of monitoring carried out in the depot found that most of the depot workers did not wear PPE properly. The lack of protection and safety practices in the workplace was one of the factors contributing to the increase of $\mathrm{MN}$ frequency among the workers exposed to the TVOC. According to Lander et al. (2000), genotoxic effects have been found among workers who do not wear PPE while working. In addition, the study by Asmah et al. (2012) shows higher $\mathrm{MN}$ frequency among farmers wearing PPE completely compared to others. 


\section{Conclusion}

In summary, there was a significant association between occupational exposure to TVOC and occurrence of $\mathrm{MN}$ in buccal epithelial cells. However, sociodemographic factors such as age, smoking status and application of PPE did not significantly cause DNA damage. This study suggests that preventive measures against exposure to TVOC in the workplace need to be reviewed and perhaps reinforced.

\section{Acknowledgement}

We would like to thank the Universiti Kebangsaan Malaysia for the financial support.Technical supports from the laboratory assistants of Environmental Health and Industrial Safety Programme are gratefully acknowledged.

\section{Author's Contributions}

All authors equally contributed in this work.

\section{Ethics}

This article is original and contains unpublished material. The corresponding author confirms that the other author has read and approved the manuscript and no ethical issues are involved.

\section{References}

Asmah, H., S.S.C. Huey, N.F. Rajab, Z.A. Hamid and A.R. Ghazali et al., 2012. 3rd Asian Conference on Environmental Mutagen and 15th Conference of Chinese Environmental Mutagen Society. Hangzhou, China, 23-26 October.

Bolognesi, C., A. Abbondandolo, R. Barale, R. Casalone and L. Dalprà, et al., 1997. Age-related increase of baseline frequencies of sister chromatid exchanges, chromosome aberrations and micronuclei in human lymphocytes. Cancer Epidemiol. Biomarkers Prevention, 6: 249-256.

Bolognesi, C., E. Perrone and E. Landini, 2002. Micronucleus monitoring of a floriculturist population from western Liguria, Italy. Mutagenesis, 17: 391-397. DOI: 10.1093/mutage/17.5.391

Bull, S., 2006. Evidence for genotoxicity of pesticides in pesticide applicators: A Review. Mutagenesis, 21: 93-103. DOI: 10.1093/mutage/gel011

Çelik, A., T. Çavaş and S. Ergene-Gözükara, 2003. Cytogenetic biomonitoring in petrol station attendants: micronucleus test in exfoliated buccal cells. Mutagenesis, 18: 417-421.

DOI: $10.1093 /$ mutage/geg022
Environmental Protection Agency, 2012. An introduction to indoor air quality: Volatile organic compound. Environmental protection agency, United States.

Gajalakshmi, P., A. Balasundaram, P. Venkatesan, S.T. Santhiya and A. Ramesh, 2002. Cytogenetic studies on spray painters in south India. Mutation Res., 514: 1-6. DOI: $10.1016 / \mathrm{S} 1383-5718(01) 00316-3$

Gemitha, G. and S. Sudha, 2013. Assessment of genotoxicity among rubber industry workers occupationally exposed to toxic agents using micronucleus assay. Iran J. Cancer Prev., 6:73-77.

Hedenstedt, A., D. Jenssen, B.M. Lidesten, C. Ramel and U. Rannug et al., 1977. Mutagenicity of fume particles from stainless steel welding. Scan. J. Work Environ. Health, 3: 203-211. DOI: 10.5271/sjweh.2776

Hessel, H., K. Radon, A. Pethran, B. Maisch and S. Gröbmair et al., 2001. The genotoxic risk of hospital, pharmacy and medical personnel occupationally exposed to cytostatic drugsevaluation by the micronucleus assay. Mutation Res., 497: 101-109. DOI: $10.1016 /$ S1383-5718(01)00236-4

Kayal, J.J., A.H. Trivedi, B.J. Dave, J. Nair and U.J. Nair et al., 1993. Incidence of micronuclei in oral mucosa of users of tobacco products singly or in various combinations. Mutagenesis, 5: 31-33.

DOI: $10.1093 /$ mutage/8.1.31

Lander, F., L.E. Knudsen, M.O. Gamborg, H. Järventaus and H. Norppa, 2000. Chromosome aberrations in pesticide-exposed greenhouse workers. Scan. J. Work Environ. Health, 26: 436-442.

Liu, Y., K. Sundqvist, S.A. Belinsky, A. Castonguay and H. Tjãlve et al., 1993. Metabolism and macromolecular interaction of the tobacco-specific carcinogen 4(methylnitrosamino)-1-(3-pyridyl)-1-butanone in cultured explants and epithelial cells of human buccal mucosa. Carcinogenesis, 14: 2383-2388.

DOI: $10.1093 / \mathrm{carcin} / 14.11 .2383$

Martins, R.A., G.A.S. Gomes, O. Aguiar and D.A. Ribeiro, 2009. Biomonitoring of oral epithelial cells in petrol station attendants: comparison between buccal mucosa and lateral border of the tongue. Environ. Int., 35: 1062-1065. DOI: $10.1016 /$ j.envint.2009.06.001

NPI, 2008. Emission estimation technique manual for Railway yard operations. National Protection Inventory.

OSHA, 2006. Personal Protective Equipment.

Pappas, R.S., G.M. Poizin, L. Zhang, C.H. Watson and D.C. Paschai et al., 2006. Cadmium, lead and thallium in mainstream tobacco smoke particulate. Food Chem. Toxicol., 44: 714-723. DOI: 10.1016/j.fct.2005.10.004 
Rosin, M.P., 1992. The use of the micronucleus test on exfoliated cells to identify anti-clastogenic action in humans: A biological marker for the efficacy of chemopreventive agents. Mutation Res., 267: 265-276. DOI: $10.1016 / 0027-5107(92) 90071-9$

Silverman, D.T., C.M. Samanic, J.H. Lubin, A.E. Blair and P.A. Stewart et al., 2012. The Diesel Exhaust in Miners study: a nested case-control study of lung cancer and diesel exhaust. J. National Cancer Institute, 104: 855-868. DOI: 10.1093/jnci/djs034

Sjödahl, K., C. Jansson, I.A. Bergdahl, J. Adami and P. Boffetta et al., 2007. Airborne exposures and risk of gastric cancer: A prospective cohort study. Int. J. Cancer, 120: 2013-2018. DOI: 10.1002/ijc.22566

Stich, H.F., M.P. Rosin and M.O. Vallejera, 1984. Reduction with Vitamin A and beta-Carotene administration of proportion of micronucleated buccal mucosal cells in Asian Betel Nut and tobacco chewers. Lancet, 1: 1204-1206. DOI: 10.1016/S0140-6736(84)91692-1

Stich, H.F., R.H.C. San and M.P. Rosin, 1983. Adaptation of the DNA-repair and micronucleus tests to human cell suspensions and exfoliated cells. Annals New York Academy Sci., 407: 93-105.

DOI: $10.1111 /$ j.1749-6632.1983.tb47816.x
Testa, A., F. Festa, R. Ranaldi, M. Giachelia and D. Tirindelli et al., 2005. A multi-biomarker analysis of DNA damage in automobile painters. Environ. Molecular Mutagenesis, 46:182-188.

DOI: $10.1002 / \mathrm{em} .20147$

Tolbert, P.E., C.M. Shy and J.W. Allen, 1992. Micronuclei and other nuclear anomalies in buccal smears: Methods development. Mutation Res., 271: 69-77. DOI: 10.1016/0165-1161(92)90033-I

Tovalin, H., M. Valverde, M.T. Morandi, S. Blanco and L. Whitehead et al., 2006. DNA damage in outdoor workers occupationally exposed to environmental air pollutants . Occup. Environ. Med., 63: 230-236. DOI: $10.1136 /$ oem.2005.019802

Vondracek, M., Z. Xi, P. Larsson, V. Baker and K. Mace et al., 2001. Cytochrome P450 expression and related metabolism in human buccal mucosa. Carcinogenesis, 22: 481-488.

DOI: $10.1093 /$ carcin/22.3.481

WHO, 1999. Monitoring Ambient Air Quality for Health Impact Assessment. 1st Edn., World Health Organization, Copenhagen, ISBN-10: 9289013516 , pp: 196. 